\title{
BMJ Open Heterogeneity in Danish lung choirs and their singing leaders: delivery, approach, and experiences: a survey- based study
}

\author{
Mette Kaasgaard (D) , 1,2 Ingrid Charlotte Andersen (D) ,,3 \\ Daniel Bech Rasmussen (D) ,1,3 Ole Hilberg (1) ,3,4 Anders Løkke (D) ,3,4 \\ Peter Vuust (iD , ${ }^{2}$ Uffe Bodtger (1D) ${ }^{1,3,5}$
}

To cite: Kaasgaard M, Andersen IC, Rasmussen DB, et al. Heterogeneity in Danish lung choirs and their singing leaders: delivery, approach, and experiences: a surveybased study. BMJ Open 2020;10:e041700. doi:10.1136/ bmjopen-2020-041700

- Prepublication history and additional material for this paper is available online. To view these files, please visit the journal online (http://dx.doi.org/10. 1136/bmjopen-2020-041700).

Received 16 June 2020 Revised 30 September 2020 Accepted 05 November 2020

Check for updates

(c) Author(s) (or their employer(s)) 2020. Re-use permitted under CC BY-NC. No commercial re-use. See rights and permissions. Published by BMJ.

For numbered affiliations see end of article.

Correspondence to MSc Mette Kaasgaard; mk@clin.au.dk

\section{ABSTRACT}

Objectives Singing is considered a beneficial leisure time intervention for people with respiratory diseases, and lung choirs have gained increasing attention. However, there is no available guideline on preferred methodology, and hence, outcomes, delivery, and benefits are unclear. The present study investigated for the first time ever emerged delivery, approach, and experiences in Danish lung choirs and their singing leaders, hypothesising the array to be heterogeneous, without disease-specific approach, and a challenging field to navigate for the singing leaders.

Setting An online survey comprising 25 questions was performed individually, May 2017, in Denmark.

Participants Current singing leaders of Danish lung choirs, identified by hand searches on the internet. In total, 33 singing leaders in formal and informal settings were identified and $20(67 \%)$ responded.

Primary and secondary outcome measures Distribution in content, delivery, and approach; level of disease-specific knowledge and modification; experience of challenges and benefits. Quantitative variables were counted, and an inductive content analysis approach was used for the qualitative study component.

Results The lung choirs were heterogeneous concerning setting, duration, and content. The approach was traditional without disease-specific content or physical activity. Most singing leaders held various academic degrees in music, but lacked skills in lung diseases. However, they experienced lung choirs as a highly meaningful activity, and reported that participants benefited both musically, psychosocially, and physically. Singing leaders were enthusiastic regarding potentials in the 'arts-and-health' cross-field and experienced an expansion of their role and overall purpose, professionally as well as personally. However, they also experienced insecurity, inadequacy, and isolation, and requested methodological guidelines, formal support, and peer network.

Conclusion Danish lung choirs are led without any disease-specific guideline or methodological approach. Further studies are needed to develop and distribute a preferred methodological approach.

Trial registration number This study is linked to clinical trial number NCT03280355 and was performed prior to data collection and results of the clinical trial
Strengths and limitations of this study

- This study is unique in several ways and is the first Danish study to explore lung choir singing leaders' experiences of methodological practice, approach, and challenges in the new field of lung choirs.

- The study allowed for an explorative approach and included components from both quantitative and qualitative research, through which we discovered new and unexpected aspects.

- Data analysis with methodological rigour and transparency strengthened validity and reliability of the study, using relevant quality tools and criteria for validation, recommended for assessing trustworthiness.

- The survey form limits the possibility of indepth insight, which could have been provided through interviews and observations and a thoroug qualitative analysis process.

- Due to the small and emerging field, our study was based on a small sample size of 20 singing leaders and may, therefore, not be representative. However, the overall study findings concur with previous studies within singing for people with respiratory diseases.

\section{INTRODUCTION}

Singing has recently become increasingly popular worldwide for people with respiratory diseases, ${ }^{1}$ as singing may address the challenges that respiratory diseases lead to. Singing is a basic human function rooted in the period of preverbal speech, ${ }^{2}$ and singing together is a basic human activity that builds and maintains the sense of social interaction, inclusion and cohesion. ${ }^{3-5}$ Singing further may enhance strength, flexibility, and coordination in the respiratory musculature, ${ }^{267}$ may reduce dyspnoea, ${ }^{2-10}$ and may have a positive impact on well-being, anxiety, and depression. ${ }^{11}$ These are all characteristics in people with respiratory diseases, and often 
difficult to handle. Chronic respiratory diseases have profound implications on an individual level, both physiologically and psychosocially, ${ }^{12}$ and the number of people with respiratory diseases is dramatically growing worldwide. ${ }^{13}$ In 2016, the prevalence of people with chronic respiratory diseases was more than 1 billion, with chronic obstructive pulmonary disease (COPD), asthma, and lung cancer among the most common chronic respiratory diseases. ${ }^{13-15}$ Specifically, COPD may lead to a vicious circle of coughing, dyspnoea, and hyperinflation, as well as possible anxiety, depression, and social isolation. ${ }^{16} 17$ In addition to pharmacological treatment, patients with COPD are often referred to a formal, evidence-based pulmonary rehabilitation programme $(\mathrm{PR})$ in order to support them physiologically, psychologically, and socially. ${ }^{13} 18$ Singing has been suggested as relevant to investigate further for potential inclusion in PR, as singing apparently addresses both the requested physiological and psychosocial aspects. ${ }^{18}{ }^{19} \mathrm{An}$ initial body of research on the significance of singing in respiratory diseases comprises a varied picture of findings from randomised controlled studies, ${ }^{28} 1920$ qualitative studies, ${ }^{521-23}$ observational studies, ${ }^{94-26}$ and literature reviews. ${ }^{27-30}$ Recently, McNamara $e t$ al. reviewed the research of the effects of singing teaching for people with COPD. ${ }^{30}$ They highlight the still limited evidence due to a low number of randomised controlled trials and generally small sample sizes. From the three included studies, the authors concluded that singing is safe and might be effective on self-reported physical health, but not on dyspnoea and respiratory-specific quality of life. It is worth noting that each study dealt with group-based singing teaching, however with a diversity in delivery time and missing information about the methods and characteristics of the control group. ${ }^{28}$ Thus, potential benefits have not yet been convincingly clinically supported, and existing approaches to lung choir methodology and delivery remain to be described, documented, and tested. ${ }^{1} 2728$

So far, overall methodological approach to lung choirs worldwide has not been systematically modified for people with respiratory diseases and their specific challenges, but rather, lung choirs have been delivered as traditional choirs. ${ }^{1}{ }^{27}$ However, a disease-specific, therapeutically oriented training approach has been developed, based on a decade's empirical fieldwork on singing for people with respiratory diseases, ${ }^{131}$ and a programme for singing leaders was offered through the British Lung Foundation from 2015 to 2020 under the name 'Singing for Lung Health' (SLH). ${ }^{132-34}$ Another disease-oriented training programme was arranged for singing leaders related to a 36-week feasibility study at Sidney De Haan Research Centre for Arts and Health, Canterbury Christ Church University. ${ }^{22}$

In a survey-based study, singing leaders evaluated that this kind of training was valuable and helped them to improve content and delivery. Importantly, they felt enabled to provide a safe environment while at the same time, they observed health benefits in their participants. However, issues related to delivery and management of group dynamics were still found challenging. ${ }^{7}$ In agreement with current quantitative research, these findings suggest that singing in a group impacts participants beneficially and that training of leaders is valuable. Nevertheless, the link between singing leaders' approaches and clinical outcomes has yet to be better understood. Hereto, there is a need to strengthen the evidence base for the significance of the leaders' approaches to delivery from the perspectives of the leaders.

Lung choirs have become increasingly popular in Denmark, and have gained considerable attention through news features on Danish television, radio, newspapers, and social media, reporting of remarkable benefits physically, psychologically, and socially from attending a lung choir. ${ }^{35-39}$ Further, lung choirs have been endorsed as a relevant activity for people with respiratory diseases by the Danish Lung Foundation since $2016 .{ }^{40}$ However, little is known about the methodological practice in the Danish lung choirs and the experiences of their singing leaders, and there are no formal, disease-oriented training programmes yet.

In the present study, we, therefore aimed to elucidate evolved delivery and approach in Danish lung choirs and to explore experiences of the singing leaders regarding managing the assignment and perceptions of benefits. With no available standardised training programme or methodological guideline, we expected the array of Danish lung choirs to be heterogeneous in relation to setting and delivery, and we expected leading a lung choir to be a challenging experience that includes feelings of insecurity for the lung choir singing leaders.

\section{METHODS}

\section{Study setting and design}

The study was conducted as an online survey, performed among Danish lung choir leaders, and was based on a quantitative study approach with categorical variables. Further, qualitative input was included from written answers in opentext fields. For survey distribution, data collection, and data storage, we used web-based software, survey tool and secure database, SurveyXact by Ramboll (Rambøll Management Consulting, Aarhus, Denmark). ${ }^{41}$

\section{Sample size and recruitment}

Potential lung choirs were identified (May 2017; by study investigator, MK (female)), and since there was no central registration of lung choirs in Denmark, the search was conducted through hand searches on the internet, comprising websites of local clubs, health centres, hospital clinics, music teaching organisations, and the Danish Lung Foundation. Search engine: Google; Search terms (translated from Danish): "COPD" OR "lung" OR "pulmonary" AND "choir" OR "singing group" OR "singing". Further, local associations (under The Danish Lung Foundation) and municipalities were contacted by telephone or email to detect potential lung choirs. Subsequently, email addresses of the identified lung choir leaders were collected and stored. There was no prior relation between MK and any study participant. 


\section{Data collection}

Each singing leader was approached directly by email, informed about the study and educational background and position of the investigator, and requested to complete the online questionnaire. Reminders were sent to non-responders after 2 weeks and again 4 weeks postinitial request, if still no response.

\section{Content of survey}

The study investigator (MK) and principal investigator (UB) developed content of the survey based on existing literature, media reports, and initial observations of lung choirs. The survey comprised 13 categorical questions on years of existence of each choir, setting, repertoire (exercises, songs and activities), educational background of the choir leaders, and any interest in further education in pathology, physiology, and disease-related methodology. To gain further and complex input on delivery, approach, and experiences, 12 questions with open-text fields were further included, regarding session content, methodological considerations, and current knowledge about respiratory physiopathology. Moreover, these questions investigated any peer-network among lung choir leaders, experiences of being a lung choir leader, and impressions of potential benefits for the choir participants. Finally, lung choir leaders were requested to pass on any good advice for future singing leaders. The survey questions are presented in online supplemental appendix 1 .

\section{Patient and public involvement}

The research did not involve participants in development, recruitment, or conduct of the study. We plan to involve participants to help us develop and carry out our dissemination strategy.

\section{Analysis}

In the absence of a formal and absolute tool for analyses in survey research, ${ }^{42} 43$ we adopted a conventional approach to analysis. Categorical questions were regarded as quantitative data, and data analyses for descriptive statistics were performed using statistical software (SPSS V.25.0). Statistical significance was reached if $p<0.05$. In the analysis of open-text fields, we applied a qualitative, inductive analytical approach inspired by Graneheim and Lundman. ${ }^{44}$ Two independent data coders (MK and ICA (female); qualitative researcher) performed the analysis, alternately and systematically through independent analysis and joint discussion, performed in three iterations. We used methods of content analysis, comprising identification of meaning units with subsequent condensation, categorisation and extraction of themes, searching for both manifest and latent aspects. After analysing results from both categorical data and the qualitative inspired analysis, MK, ICA, and UB (male) identified thematic areas in relation to study outcomes, and interpreted and triangulated possible meanings, retrieved from the data material. "Strengthening the Reporting of Observational Studies in Epidemiology Statement" (STROBE) checklist for cohort studies for the quantitative study components and "Consolidated criteria for reporting qualititive research"
(COREQ) checklist for interviews and focus groups for the qualitative study components are provided in online supplemental files.

\section{RESULTS}

In total, 33 lung choirs were identified. The response rate was $67 \%$ (20 responders) including partial responses from three responders $(9 \%)$.

\section{Characteristics of lung choirs}

Table 1 shows heterogeneity concerning choir name, size, duration of sessions and urban/rural areas. The majority of the choirs $(70 \%)$ had been established within the past 3 years, they were mainly founded in local formal music teaching organisations, and they mostly rehearsed once every week.

\section{Characteristics of singing leaders}

Singing leaders' educational background and years of experience were heterogeneous as shown in table 2. A total of $95 \%$ declared to be 'interested' or 'maybe interested' in gaining further knowledge and training within the field, yet only $20 \%$ had independently consulted health professionals to obtain more knowledge on lung diseases prior to taking up this new work assignment. The majority had interviewed choir participants and/or had read a short folder from the Danish Lung Foundation or similar with information on COPD.

\section{Characteristics of methodological approach}

Table 3 depicts the singing leaders' responses about their methodological approach. The majority reported to use traditional choir components such as piano accompaniment, text sheets, and musical repertoire of canons or simple polyphony. Only $15 \%$ included supplementary movement or dancing consistently during the choir session.

\section{Themes derived from open-text fields}

Through the iterations of the inductive analysis process, we identified three essential themes in relation to experiences of the singing leaders in navigating in a new and emerging field: (1) Performing meaningful teaching modified for patients with respiratory diseases, (2) Navigating through the 'arts and health' cross-field, and (3) Walking on the pioneer's pathway. These three themes were then further divided into subthemes, represented in selected quotes from the participating singing leaders, which are depicted in boxes $1-10$.

\section{Performing meaningful teaching modified for patients with respiratory disease}

Singing leaders' perspective

The singing leaders reported to have experienced a change in their perspective on the potentials of singing, on the choir participants, and on their role 


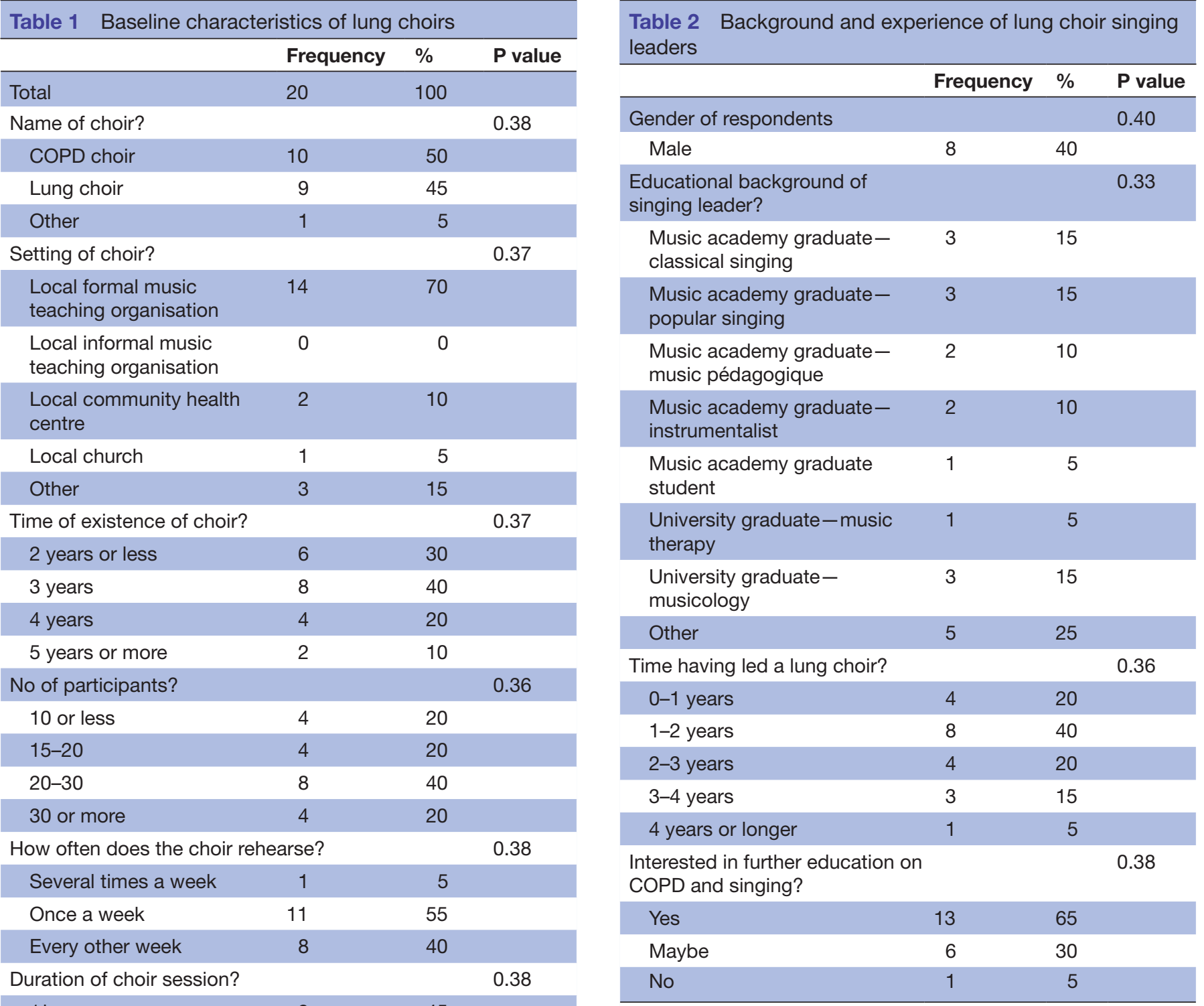

\begin{tabular}{llll}
\hline 1 hour & 9 & 45 & \\
\hline 1.5 hours & 6 & 30 & \\
\hline 2 hours & 4 & 20 & \\
\hline 3 hours & 1 & 5 & 0.36 \\
$\begin{array}{l}\text { Population density } \\
\begin{array}{l}\text { Thinly populated area (non- } \\
\text { responders) }\end{array}\end{array}$ & $9(5)$ & 45 & \\
$\begin{array}{l}\text { Intermediate density area } \\
\text { (non-responders) }\end{array}$ & $7(5)$ & 35 \\
$\begin{array}{l}\text { Densely populated area } \\
\text { (non-responders) }\end{array}$ & $4(3)$ & 20 \\
\hline
\end{tabular}

Data are presented as numbers (\%), and $p$ values calculated with Pearson $\chi^{2}$ test. All analyses were performed in SPSS V.25.0, .

COPD, chronic obstructive pulmonary disease.

as a singing leader, personally and professionally. The role as a lung choir leader differed from being a leader of conventional choirs, and their former professional 'toolbox' was no longer sufficient.

Data are presented as numbers (\%), and $p$ values calculated with Pearson $\chi^{2}$ test. All analyses wereperformed in SPSS V.25.0,

COPD, chronic obstructive pulmonary disease.

Instead, deeper personal aspects regarding role and interaction evolved, leading to a new mind-set in relation to session content, preferred outcome of the choir sessions, and methodological approach (box 1).

The singing leaders and the participants began a joint journey in a new field, with session content developed dynamically through a co-creation process and with the participants regarded as experts (box 2).

,Singing became a refuge and a catalyst of hope, revitalisation, and new self-esteem for the participants, and participants further often confided in the singing leader, sharing both success and vulnerabilities. These aspects added yet another aspect to the role and to the relationship and led to yet another role: the singing leader as a confidential witness who believed in the participants (box 3). 


\begin{tabular}{|c|c|c|c|}
\hline & Frequency & $\%$ & $P$ value \\
\hline $\begin{array}{l}\text { Does the choir sing unison or } \\
\text { polyphony? }\end{array}$ & & & 0.38 \\
\hline Unison only & 6 & 30 & \\
\hline $\begin{array}{l}\text { Occasional canons and } \\
\text { simple polyphony }\end{array}$ & 13 & 65 & \\
\hline Consistent polyphony & 1 & 5 & \\
\hline $\begin{array}{l}\text { Use of piano accompaniment } \\
\text { during session? }\end{array}$ & & & 0.40 \\
\hline $\begin{array}{l}\text { Consistently during choir } \\
\text { session }\end{array}$ & 16 & 80 & \\
\hline Occasionally & 2 & 10 & \\
\hline Rarely & 0 & 0 & \\
\hline Never & 2 & 10 & \\
\hline $\begin{array}{l}\text { Use of music sheets during } \\
\text { session? }\end{array}$ & & & 0.38 \\
\hline Sheets (notes and text) & 1 & 5 & \\
\hline Sheets (text) & 13 & 65 & \\
\hline Learning by ear & 2 & 10 & \\
\hline Mix & 4 & 20 & \\
\hline $\begin{array}{l}\text { Use of movement or dancing } \\
\text { during session? }\end{array}$ & & & 0.37 \\
\hline Never & 3 & 15 & \\
\hline Rarely & 7 & 15 & \\
\hline Occasionally & 7 & 35 & \\
\hline Consistently & 3 & 15 & \\
\hline
\end{tabular}

Data are presented as numbers (\%), and $p$ values calculated with Pearson $\chi^{2}$ test. All analyses were performed in SPSS V.25.0,

Response from the choir participants, as reported by the singing leaders

The singing leaders reported participants' direct feedback on lung choir attendance, further described their own subjective observations on participants' gains physically, psychologically, socially, and musically (box 4), and subsequently, the importance of attendance (box 5).

\section{Box 1 A different role}

It was quite difficult at first... how should I approach it, how ill would they be, how much would they be able to handle? I have had to try different things and have now 'found my own way' of handling it.'

- 'It is a much more personal job compared to leading other choirs! We have become much more mutually acquainted and gotten to know each other's personal life stories and challenges. And after all they are very ill and may die. Which some do along the way.'

- 'Leading the choir is so life-affirming and meaningful, because they so intensely express what singing and participating means to them.'

- 'Lower your personal musical ambitions. Focus on well-being and joy. Be yourself. Be present.'

\section{Box 2 A co-creation process}

- 'I always ask the participants what they think works. They are the true experts. In this way we grow together.'

> 'Ask — listen — and then learn and adjust.'

- 'They are actually better at performing breathing exercises than the other choirs I use to lead. And this is because they have tried it before, I found out.'

In relation to physical aspects, some participants reported that their breathing had improved due to the new everyday skills adapted from the choir. Moreover, some reported improved sleeping quality, now being able to quit use of home-oxygen supply, and some reported that their lung function had improved in clinical lung function tests.

Regarding psychological aspects, participants experienced becoming happy from singing. Some experienced an increase in self-esteem and everydaymastering, now being capable of more than they thought and gaining access to hidden resources. Socially, participants experienced breaking feelings of being socially isolated, and enjoyed being among like-minded peers where the joy of music transformed and replaced the ubiquitous everyday disease focus. Further, they experienced making friends among the other choir members and becoming each other's significant, mutual network.

The singing leaders observed a profound growth in relation to the musical aspects, comprising increase in musical competence, complexity, and expression ability, as well as improved fitness, vocally and physically (box 4).

In general, there was a high compliance and frequency in attendance. This is reflected in the participants' opinion on importance of attendance and in their commitment and active contribution on several levels (box 5).

\section{Navigating through the cross-field of 'arts and health'}

Being the singing leader of a lung choir required considerations of many, new aspects. Combining singing with respiratory disease and health aspects was perceived

\section{Box 3 The singing leader as confidential witness}

'The 'system' has various views on singing and its potential health benefits. Unfortunately, some of my singers have experienced that their general practitioner has laughed at them when they told that they attend a lung choir.'

- 'I would of course like to get feedback from them, but they never say anything when I ask them as a group. Instead they approach me (individually) after the choir session. They tell me that for many years, they have been told that they are guilty of their situation. Due to this, they are very shy and don't speak up.'

- 'They become filled with hope and confidence that they can improve their lung capacity — or can fight to achieve it. It seems extremely important to them to tell me about the recent results of their lung function test.' 


\section{Box 4 Perceived gains and benefits}

\section{Physical aspects}

- Improved oxygen saturation. Some describe that they sleep much better after having attended the choir. They have increased focus on good breathing technique in their everyday life.'

- 'Several participants have returned from check at the hospital and have reported that their lung function has improved. And several tell me that they find it easier to breathe after a choir session.

- 'A lot of the participants have improved their lung function, some find it easier to handle breathlessness, and a few participants have ceased to use home oxygen supply.'

- 'One of the participants told me that she had now become stronger and able to comb her hair nicely again.'

\section{Psychological aspects}

- They are so happy and uplifted after a choir session, and they so often tell me this.'

- 'Better mastering of their disease. They experience to be able to manage their lives. And they experience less loneliness.'

- 'Everybody is so joyful, and we all experience growth. They care for each other and for me.'

- 'They tell me they become happy. Singing helps them a lot — also in relation to their self-esteem.'

\section{Social aspects}

- 'Making new friends. All being in the same boat. Positive social contact. Being in a social space where we work with the key issues related to COPD, but without focusing on the disease at all.'

- 'A strong social cohesion has emerged, and we have also been on some daytrips together. I think it is important that they don't feel that they are patients all the time.'

- 'To many of the participants, the lung choir is a space of refuge, meeting, unfolding, training. A space where they often 'forget' that they are ill, because we focus on singing. A space where they are capable of much more than they thought. A space where we laugh a lot, a space for humour, fellowship and caring for each other.'

- 'Often, I have experienced that the participants become each other's important mutual social network in case if illness. They stop by or take care of pets and so on if someone is in the hospital.'

\section{Musical aspects}

- The choir has developed a lot, musically. At first, they were only capable of singing unison songs and everything had to be divided into small bits. Now they are able to sing polyphonic songs, and they are more capable of stretching the phrases. Their voices also become stronger — with less hoarseness.'

- 'In the beginning, they thought that the song pitch was too high, even though that I transposed to a lower key. Now I almost never hear anybody saying this, also even though I have actually transposed to a higher key. It is obvious that their voices have improved.'

- 'When I present a new song, many of the participants are reserved. They feel that the phrases are far too long, the notes are too high and the song is far too difficult. They feel limited due to lack of oxygen, and they are afraid that I will make them sing something that will make them too breathless. But often it isn't long before they ca actually easily sing the song. And then they get that feeling of mastering.'

highly beneficial by the singing leaders. For example, singing was perceived as a shortcut to health benefits and as a shortcut to processing emotions (box 6).

Singing further provided a refuge where participants were not seen as patients, and music became a catalyst for a

\section{Box 5 Importance of attendance}

- It has surprised me how much it means to them to attend the choir sessions. It really seems to be important to them.'

- 'A common thing for my singers is how loyally they show up for choir rehearsal, and they really benefit from attending. My oldest participant is 88 years old, and she often states that Thursday (choir day) is simply the best day of the week!'

- 'It has been so easy to establish a positive spirit in relation to singing. Many of the participants arrive early before we start, and they help out arranging chairs and finding sing books. It is really helpful.'

positive atmosphere with leader and participants as equally valued, and with mutual empathy, compassion, and humanity as focal points (box 7).

However, the balance between singing and health aspects was also challenging, and singing leaders experienced considerable insecurity and uncertainty concerning appropriate methodological approach and lesson content as well as rating any potential risks, adverse events, or dangers (box 8).

\section{Walking a pioneer pathway}

The new combination of singing and respiratory diseases inevitably made the singing leaders enter a role of being pioneers. This was both reflected in the way the surrounding world looked on lung choirs (box 9) and in the way the singing leaders invented methodology and approach, dynamically and exploratory (boxes 2 and 10). Their professional experiences must be transformed and translated into the new field, and this explorative approach was both perceived as exiting, but at the same time as a great responsibility. The

\section{Box 6 Singing as a shortcut}

\section{Singing as a shortcut to health benefits}

- To pass on good breathing exercises and exercises that make a connection with the support musculature that surrounds the lungs. Hereby the singers get more tools to get rid of the air that is aggregated in the lungs.'

- 'My experience is that the singers benefit from learning traditional singing technique. Especially in relation to the expiratory airflow, where they say that they really benefit from learning how to control their breathing.'

- 'Breathing exercises that help them pacify the thorax and try to get the air all the way down. This is extremely difficult for them, but it makes a huge difference when they learn how to. Not only in singing, but also in their daily life, especially for those that hyperventilate and need to breathe calmer and deeper in order to regain control.'

\section{Singing as a shortcut to process emotions}

- Picking songs with lyrics that create feelings of fellowship and disease mastering, and songs that are moving. The choir is a good space for containing emotions together.'

- 'Creating a positive spirit and facilitating a space where the singers feel free to sing without performance anxiety, and where they feel free to be present with the emotions that arise within them.'

- 'I choose songs that put words to both joy and sorrow, and often pick lyrics with an existential content.'

- 'Singing creates fellowship in a group of people that often experience profound loneliness.' 


\section{Box 7 Participants not seen as patients}

It is highly beneficial to merge musical and health-related aspects. There is so much to gain.'

- 'We have chosen not to talk and focus on lung disease - and this means: Not to regard them as patients.'

- 'It has surprised me how little I think of the participants as people with a severe illness. There is so much positive spirit and vocal sound!'

- 'I focus on the people rather than on the disease - if needed, they will help you becoming aware of their challenges.'

- 'Just focus on the joy of singing and the rest will fall into place. Just meet them at the same eyelevel.'

pioneer role led to feelings of insecurity, isolation, and loneliness, not being sufficiently able to depend on former knowledge and lacking profound experience, peer network, and methodological guideline (box 10).

\section{DISCUSSION}

In the present study, based on self-reported information from 20 lung choir singing leaders in 2017, we investigated delivery, approaches, and experiences of current lung choir singing leaders in Denmark. The majority of Danish lung choirs $(70 \%)$ had been established within the past 3 years, and were offered in $14(14.3 \%)$ municipalities in 2017. The newly emerged field of Danish lung choirs was delivered heterogeneously and with a traditional choir approach without any disease-specific methodology, and singing leaders regarded leading lung choirs as an eye-opening and enriching experience and found attendance highly beneficial to the participants. However, singing leaders also associated leading lung choirs with feelings of insecurity, inadequacy, and isolation. The following section will discuss implications and validity of the present study, and finally, provide suggestions for the next steps towards high-quality lung choir delivery.

The Danish singing leaders were highly professionally skilled, having 5 years of academic musical education, which differs from the British programme, SLH, in which singing leaders had more heterogeneous backgrounds. ${ }^{32}$ Basically, the Danish singing leaders felt highly confident in relation to their professional choir leading skills. However, in lung choirs, they experienced insecurities in relation to choosing an appropriate methodological

\section{Box 8 A challenging balance}

It is really challenging to find the balance between rehabilitation/ training and music/choir.'

- 'I would like an introduction to different lung diseases (COPD, asthma etc), so you would know the challenges of each disease and how the disease affects them.'

- 'I need more knowledge about COPD in relation to what goes on in the lungs physiologically, and how good breathing technique would be helpful. Knowledge about how breathless it is OK to get — can it ever become dangerous?'

\section{Box 9 The eyes of the surrounding world}

'The 'system' has various views upon singing and its potential health benefits. Unfortunately, some of my singers have experienced that their general practitioner has laughed at them when they told that they attend a lung choir.'

approach, and they feared being responsible for any potential adverse effects in choir participants' health.

Requested outcomes in the new field were unclear to the singing leaders as well as the appropriate level of any disease-targeted focus. Due to this, they mainly adopted a traditional choir approach and solely focused on the musical aspects; however, with experimental integration of participants' perspectives on respiratory diseases. The Danish singing leaders generally experienced a lack of support from organisations, health professionals, and peer network, which led to further feelings of vulnerability, isolation, and loneliness. Similar experiences were described in a previous study exploring interaction between people with mental health problems and museum educators. ${ }^{45}$ These Danish museum educators were offered no training prior to intervention, contrary to museum educators in similar British projects. While experiencing confidence in relation to their professional skills, this qualitative study showed that being out of the comfort zone in the new assignment induced feelings of insecurity and anxiety. Further, the museum educators had concerns about potential health risks for the participants. ${ }^{45}$

As previously addressed by Goldenberg ${ }^{27}$ and Cave $e t$ $a l .,{ }^{1}$ there are currently no firm or widespread guidelines on lung choir delivery. Indeed, recommendations do exist on psychological approach by the singing leader ${ }^{26}$ and on focus on breathing, posture, and body awareness as well as indications on suitable and easily learnt repertoire.$^{32}$ Little is available in other languages than English, and it is furthermore not likely that singing leaders with a non-scientific background gain access to scientific literature. Therefore, dissemination of recommendations to singing leaders is crucial as well as a more detailed methodological approach on preferred lung choir delivery including specific directions for content and form. This could include didactical planning and sessions design with specific descriptions of suitable exercises concerning breathing, posture, and voice, and directions for applying

\section{Box 10 The eyes of the singing leader}

'It was quite difficult at first... how should I approach it, how ill would they be, how much would they be able to handle? I have had to try different things and have now 'found my own way' of handling it.'

- 'I need more knowledge about COPD in relation to what goes on in the lungs physiologically, and how good breathing technique would be helpful. Knowledge about how much breathlessness is $\mathrm{OK}$ - can it ever become dangerous?' 
a therapeutic approach to the musical repertoire, thus addressing disease-specific characteristics such as tension in jaw and neck, hyperinflation, and lack of flexibility in the respiratory musculature.

Preceding specialised training has been shown to be highly relevant to provide singing leaders with competence and confidence. ${ }^{32} \mathrm{~A}$ generic guideline and training programme in lung choirs may ensure more qualified delivery with predictable benefits, and may further prevent overexertion, exhaustion of accessory muscle use ${ }^{34}$ or other adverse events in the choir participants. ${ }^{1}$ Adverse events in singing training have not been studied systematically, but the available systematic reviews found low incidences and no singing-specific adverse events. ${ }^{730}$ We recommend the same precautions as in PR to avoid adverse events: adhering to usual COPD therapy (including oxygen supplement) and warming up prior to singing. ${ }^{18}$ Further, we recommend an open dialogue with the participants and an ongoing awareness, observation, and registration, including keeping a logbook of sessions, responses, and reflections. Likewise, we recommend building peer network with sharing of experiences, affiliating health professionals for consultancy in cases of doubt, and exploring current research literature, recommendations, and body of evidence.

In our present study, navigating in the new field, on the other hand, also allowed for multiple, unexpected benefits for the singing leaders, professionally as well as personally. The experience of no longer solely being able to rely on their musical skills led to an experimental and creative approach in the attempt of meeting and embracing the disease-related limitations in the choir participants. New dynamics emerged, interpersonally as well as intrapersonally, and there was a change in preferred outcomes of the choir and the singing leaders' overall professional purpose. Our study thus highlights that leading a lung choir requires multiple qualifications and competences besides professional musical and voice teaching skills of the singing leaders. This aspect has previously been addressed by Goldenberg ${ }^{27}$ who further suggests reaching out for interdisciplinary cooperation in order to ensure ideal delivery and to meet the needs of participants. In a previous feasibility study from 2013 by Haan and Clift, ${ }^{26}$ participants also stated that the singing leaders needed multiple qualities besides their professional skills, and specifically emphasised facilitator qualities and virtues such as having a 'sense of humour', being 'caring, understanding, kind, helpful', and showing a 'no pressure' attitude. ${ }^{26}$ The Danish singing leaders reported building close emotional and confidential relationships with choir participants and, furthermore, of significant feelings of appreciation by the participants. These aspects were also seen in a qualitative study from 2016 on contemporary visual artists' role when interacting with employees in different work places. ${ }^{46}$ The artists felt strong appreciation for their personal commitment' and received 'a lot of emotional response' from the employees. Further, the artists experienced adopting a change in outcomes and approach in the new work assignment, and often found it challenging to balance 'performing emotional work' with still trying to hold on to professional skills and ambitions. ${ }^{46}$ Concurring with the experiences of the singing leaders in our study, this underpins the need for offering training in relation to the change in professional role and specific outcomes of the activity. This would be relevant in order to provide optimal delivery, to handle vulnerable people emotionally and ethically with clear professional boundaries, and further, to avoid a potential risk of artists' emotional burnout. ${ }^{4546}$

In our present study, the significance of participating was emphasised, and lung choirs created a space that became a catalyst for many and complex processes. Based on perceptions of the singing leaders in this present study, lung choirs were highly beneficial to the participants, physically, psychologically, socially, and musically. Apart from improving respiratory and physical well-being, participants reported that singing also brought significant growth in confidence, self-esteem, and feelings of succeeding. They further experienced the rise of a strong and important sense of community in the lung choir and that attendance grew to become of significant importance to them. The lung choir became a positive space with mutual acceptance; a space that broke the loneliness and made it possible to process difficult emotions without anxiety or feeling odd. Previous studies on lung choirs have also described improved management of dyspnoea, increased quality of life, and experiences of joy and meaning. ${ }^{19-22} 24$ Based on the SLH study on singing leaders' experiences, participants achieved similar benefits as from physical training and achieved new coping strategies, yet without even noticing it ${ }^{32}$ which concurs with findings from our study. Singing leaders in the SLH programme described singing as a fun, positive, and hugely beneficial' activity to the participants, ${ }^{32}$ which concurs with the study on patient experiences, where attendance is described as having even become indispensable $?^{34}$ In concurrence with our findings on the significance of sense of community and personal growth, a qualitative study by Simony $e t$ al. ${ }^{47}$ found that a positive space in group-based PR in patients with COPD created an important sense of community. Participation improved the ability to process and manage the difficulties in the disease, practically as well as existentially, and allowed for an improved self-image and new horizons. ${ }^{47}$ However, some participants also experienced the PR course as a 'stressful overload'. ${ }^{47}$ High drop-out-rates are wellknown within PR in general, and there is a need for investigating new relevant and motivating activities for lung patients that both address physiological and psychosocial aspects. ${ }^{1318} 48$ The Danish singing leaders reported strong enthusiasm, engagement, and commitment among the participants, and a high frequency of attendance, which similarly was reported in British singing leaders. ${ }^{32}$ The rise of a strong sense of community and mutual support among the participants, as reported in the present study, also existed beyond the choir sessions. 
These findings concur with previous findings on social support and cohesion. ${ }^{22}{ }^{49}$ Singing is perceived as a social and motivating activity without focus on the disease, and singing further creates a 'new culture' in which participants gain the benefits of physical training without noticing it. ${ }^{32} 34$

\section{Study strengths and limitations}

Strengths

The present study can be considered unique in several ways and has a number of strengths. First, this is the first study to investigate delivery of lung choirs having emerged independently and informally and to include perspectives and experiences of the singing leaders in such field. Second, the singing leaders were given wide possibilities to answer freely and at their own pace, allowing for elaboration of preferred issues and perspectives. This probably contributed to relevant complexity and depth in the data material. Third, by allowing for an explorative approach and including components from a qualitative research, we discovered new and unexpected aspects. These aspects were seen in relation to new personal and professional perspectives of the singing leaders; in relation to the experiences, benefits, and growth of the choir participants; and in relation to the pioneer pathway leading to new roles, dynamics, and mutual exchange of resources. Fourth, for the aim of strengthening validity and reliability of the study, we conducted our data analysis with methodological rigour and transparency. We used relevant quality tools and criteria for validation, comprising the concepts of credibility, dependability, and transferability, recommended for assessing trustworthiness. ${ }^{44}$ The aspect of credibility was strengthened by the choice of a survey-based study type, which we found the most appropriate to reach singing leaders all over the country and in different settings. Moreover, the inclusion of open-text questions allowed for complex and unexpected aspects. Further, trustworthiness was supported by the systematic and transparent analysis process with two independent data coders and discussions through several iterations in relation to settling for units of meaning and thematic areas supports, and by the subsequent triangulation with the categorical data and the agreement with co-researchers on interpretation and meaning. As data were not collected over time but instead only collected once and entered directly into the database, there was no risk of inconsistency during data collection, ${ }^{44}$ and therefore, trustworthiness through the aspect dependability was not affected in this study. We suggest that the aspect transferability is well supported in our study, since the majority of our findings on delivery, singing leaders' experiences, and participants' benefits concur with the findings from previous studies. However, our study also adds new aspects and perspectives that have not previously been described or addressed and which may be relevant in development in future programmes and guidelines.

\section{Limitations}

The study also has a number of limitations with regard to both methodology and validity of conclusions. First, the study was based on an online survey with a quantitative design. However, the survey also comprised open questions from which many relevant aspects appeared, which would not have been provided similarly through categorical variables solely. The survey form, though, limits the possibility of an in-depth insight, which could have been provided through interviews and observations, and data, therefore, are not based on a thoroughly qualitative explorative process. As described above, we, however, aimed for rigour in methodological quality, and adapted a systematic and transparent analysis process with inspiration from qualitative methods, and thus consider findings relevant, beneficial, and valid. Subsequently, we also found that the joint analysis of both data types mutually supported and complemented each other. Second, the study was solely based on the singing leaders' subjective perspectives on experiences and benefits and further, the responding singing leaders were probably more likely to feel competent and confident than non-responders, which may have caused recall bias. Field observations allow for a more objective impression of the delivery, and in-depth interviews allow for direct perspectives on participants' experiences. This, however, was outside the scope of this study. Third, due to the small and emerging field, this study is also based on a small sample size of 20 singing leaders and may therefore not be representative, despite our effort to recruit all possible singing leaders and to contact non-responders among those identified and approached. However, the overall study findings concur with previous studies in regard to traditional approach ${ }^{27}$ and to British singing leaders' experience of benefits of the participants. ${ }^{32}$ Fourth, our study did not include reporting of age, years of postgraduate work experience, or bias in responders and non-responders. These data would have been relevant in order to get insight into the actual delivery across the country, as it is a likely possibility that only the most engaged, well educated, and resourceful singing leaders responded.

\section{CONCLUSIONS AND PERSPECTIVES}

Currently, the field of Danish lung choirs is characterised by traditional delivery and approach, by a lack of diseasespecific knowledge and methodology among the singing leaders, and by feelings of insecurity and inadequacy. However, the field is also characterised by much enthusiasm and by experiences of significant benefits, physically, psychosocially, and musically. Lung choir singing facilitates new resources and perspectives and supports well-being and personal growth in both singing leaders and lung choir participants.

Overall, the present study confirms previous perceptions of lung choirs as a unique, beneficial, and motivating activity that may be relevant and meaningful to the rapidly growing number of people with respiratory 
diseases worldwide. However, the present study further confirms the growing awareness regarding developing an international guideline and to ensure high-quality delivery and homogeneous outcomes when entering a health-related field without an appropriate educational background.

There are numerous evidence gaps concerning singing training in COPD, such as optimal training of singing leaders, optimal delivery, impact on physical exercise capacity, role of singing training in disease management, and mechanisms behind the improvement in perceived benefits.

To develop future international guidelines, there is a need for investigating and consolidating current lung choir practices in larger, clinical trials. High-quality qualitative or mixed-methods studies will add unique information on patients' perspectives on relevant outcomes and approaches, and cross-national surveys are needed for proper implementation and local tailoring.

\section{Author affiliations}

${ }^{1}$ Pulmonary Research Unit Region Zealand (PLUZ), Department of Respiratory Medicine, Naestved and Slagelse Hospital, Naestved and Slagelse, Denmark ${ }^{2}$ Center for Music in the Brain, Department of Clinical Medicine, Faculty of Health Sciences, Aarhus University \& The Royal Academy of Music, Aalborg/Aarhus, Aarhus, Denmark

${ }^{3}$ Department of Regional Health Research, Faculty of Health Sciences, University of Southern Denmark, Odense, Denmark

${ }^{4}$ Department of Respiratory Medicine, Hospital Lillebaelt, Vejle, Denmark

${ }^{5}$ Department of Medicine, Zealand University Hospital, Roskilde, Denmark

Acknowledgements The authors would like to thank the Danish singing leaders who participated in the survey and willingly contributed with their experiences and considerations. A special thanks to founder of "Singing for Lung Health", music therapist, singing teacher, Phoene Cave, for reading the manuscript and providing important intellectual content.

Contributors All authors meet the ICMJE criteria for authorship. Mette Kaasgaard (MK), Uffe Bodgter (UB), Ole Hilberg (OH), Anders Løkke (AL) and Peter Vuust (PV) contributed to the conception and design of the study. The study investigator (MK) and principal investigator (UB) developed the survey. No participant was involved in developing the survey. MK recruited study participants, collected the study data, developed applications for grants and approval assignments, and made registry at ClinicalTrial.gov. MK, Daniel Bech Rasmussen (DBR) and UB performed the quantitative analysis, and MK and Ingrid Charlotte Andersen (ICA) performed the qualitative analysis. MK, UB and ICA contributed to the interpretation of the data. MK was responsible for drafting the manuscript, and all of the authors provided critical review of drafts for important intellectual content and approved the final version submitted for publication.

Funding The present study was part of a Danish PhD project, funded by the Tryg Foundation, ID 111562 (DKK 967.470), The Danish Health Foundation, 18-B-0067 (DKK 200.000), Aase og Ejnar Danielsen's Foundation, ID 10-001745 (DKK 75.000), A.P. Møller and Hustru Chastine Mc-Kinney Møller's Foundation (Fonden til Lægevidenskabens Fremme), ID 16-204 (DKK 40.000), The Danish Lung Foundation, ID 179031-24-03-2017 (DKK 125.000), Naestved, Slagelse and Ringsted Hospitals' Research Fund (DKK 633.974), Danish Central Region, ID 1-3072-141-12 (100.000 DKK), Region Zealand, ID 180886, 13-000835 (DKK 314.500), and Aarhus University (DKK 450.000). All research grants were used for salary to study investigator MK, running costs and equipment. Participants did not receive any economical compensation for study participation.

Competing interests MK holds a Diploma Graduate Degree from The Royal Danish Academy of Music in Vocal Studies. PV is leader of the research centre, Centre for Music in the Brain. The other authors had no prior experience or knowledge within any field of singing. None of the authors had prior relations to any study participant. No author or close relatives have economic interests within the field of singing including lung choirs.
Patient consent for publication Not required.

Ethics approval This study is included in the main protocol for the randomised controlled trial, "'The Effects of Singing Training for Patients with Chronic Obstructive Pulmonary Disease (COPD), and approved by The Regional Committees on Health Research Ethics, Region Zealand, Denmark (number SJ-597), and by the Danish Data Protection Agency (number REG-049-2017). The study follows the principles of the Declaration of Helsinki.

Provenance and peer review Not commissioned; externally peer reviewed.

Data availability statement All data relevant to the study are included in the article or uploaded as online supplemental information.

Supplemental material This content has been supplied by the author(s). It has not been vetted by BMJ Publishing Group Limited (BMJ) and may not have been peer-reviewed. Any opinions or recommendations discussed are solely those of the author(s) and are not endorsed by BMJ. BMJ disclaims all liability and responsibility arising from any reliance placed on the content. Where the content includes any translated material, BMJ does not warrant the accuracy and reliability of the translations (including but not limited to local regulations, clinical guidelines, terminology, drug names and drug dosages), and is not responsible for any error and/or omissions arising from translation and adaptation or otherwise.

Open access This is an open access article distributed in accordance with the Creative Commons Attribution Non Commercial (CC BY-NC 4.0) license, which permits others to distribute, remix, adapt, build upon this work non-commercially, and license their derivative works on different terms, provided the original work is properly cited, appropriate credit is given, any changes made indicated, and the use is non-commercial. See: http://creativecommons.org/licenses/by-nc/4.0/.

\section{ORCID iDs}

Mette Kaasgaard http://orcid.org/0000-0003-3833-2943

Ingrid Charlotte Andersen http://orcid.org/0000-0003-2558-0673

Daniel Bech Rasmussen http://orcid.org/0000-0003-1213-9483

Ole Hilberg http://orcid.org/0000-0002-3075-3463

Anders Løkke http://orcid.org/0000-0002-6905-4141

Peter Vuust http://orcid.org/0000-0002-4908-735X

Uffe Bodtger http://orcid.org/0000-0002-1231-9209

\section{REFERENCES}

1 Cave P, Lewis A, Fancourt D. Singing for Lung Health. In: The Routledge companion to interdisciplinary studies in singing. III, 2020.

2 Bonilha AG, Onofre F, Vieira ML, et al. Effects of singing classes on pulmonary function and quality of life of COPD patients on-line early 08-10-2008 on-line early 08-10-2008. Int J Chron Obstruct Pulmon Dis 2008;4.

3 Stewart NAJ, Lonsdale AJ. It's better together: The psychological benefits of singing in a choir. Psychol Music 2016;44:1240-54.

4 Weinstein D, Launay J, Pearce E, et al. Singing and social bonding: changes in connectivity and pain threshold as a function of group size. Evolution and Human Behavior 2016;37:152-8.

5 Skingley A, Clift S, Hurley S, et al. Community singing groups for people with chronic obstructive pulmonary disease: participant perspectives. Perspect Public Health 2018;138:66-75.

6 Irons JY, Kenny DT, McElrea M, et al. Singing therapy for young people with cystic fibrosis: a randomized controlled pilot study. Music Med 2012;4:136-45.

7 Irons JY, Petocz P, Kenny DT, et al. Singing as an adjunct therapy for children and adults with cystic fibrosis. Cochrane Database Syst Rev 2019;7:CD008036.

8 Lord VM, Cave P, Hume VJ, et al. Singing teaching as a therapy for chronic respiratory disease--a randomised controlled trial and qualitative evaluation. BMC Pulm Med 2010;10:41.

9 Engen RL. The Singer's breath: implications for treatment of persons with emphysema. J Music Ther 2005;42:20-48.

10 Canga B, Azoulay R, Raskin J, et al. AIR: Advances in Respiration Music therapy in the treatment of chronic pulmonary disease. Respir Med 2015;109:1532-9.

11 Gebauer L, Vuust P. Music interventions in health care. Technical University of Denmark, 2014.

12 Kelly C, Lynes D. Psychological effects of chronic lung disease. Nurs Times 2008;104:82-5.

13 Loddenkemper R, Gibson GJ, Sibille Y, et al. European lung white book in chronic obtructive pulmonary disease, 2013.

14 Bousquet J, Dahl R, Khaltaev N. Global alliance against chronic respiratory diseases. Allergy 2007;62:216-23. 
15 Marciniuk D, Rabe KF, Reeves E, et al. Respiratory diseases in the world. realities of today - opportunities for tomorrow. African J Respir Med 2014.

16 Heslop K. Non-Pharmacological treatment of anxiety and depression in COPD. Nurse Prescr 2014.

17 Brenes GA. Anxiety and chronic obstructive pulmonary disease: prevalence, impact, and treatment. Psychosom Med 2003;65:963-70.

18 GOLD. Global strategy for prevention, diagnosis and management of COPD. Global Inititiative For Chronic Obstructive Lung Disease (2019), 2020.

19 Liu H, Song M, Zhai Z-H, et al. Group singing improves depression and life quality in patients with stable COPD: a randomized community-based trial in China. Qual Life Res 2019;28:725-35

20 Lord VM, Hume VJ, Kelly JL, et al. Singing classes for chronic obstructive pulmonary disease: a randomized controlled trial. BMC Pulm Med 2012;12:69.

21 McNaughton A, Aldington S, Williams G, et al. Sing your lungs out: a qualitative study of a community singing group for people with chronic obstructive pulmonary disease (COPD). BMJ Open 2016;6:e012521.

22 Skingley Aet al. 'Singing for Breathing': Participants' perceptions of a group singing programme for people with COPD. Arts Heal 2014.

23 Skingley A, Price S, Clift SM, et al. Singing for Breathing' groups for people with COPD: participants' experiences. Arts Heal 2013;6:59-74.

24 Morrison I, Clift S. A UK feasibility study on the value of singing for people with chronic obstructive pulmonary disease (COPD) September 2011 to June 2012. Eur J Public Health 2017.

25 Goodridge D, Nicol JJ, Horvey KJ, et al. Therapeutic singing as an adjunct for pulmonary rehabilitation participants with COPD: outcomes of a feasibility study. Music Med 2013.

26 Haan M, Clift S. An evaluation of community singing for people with COPD (chronic obstructive pulmonary disease) final report, 2013.

27 Goldenberg RB. Singing lessons for respiratory health: a literature review. J Voice 2018;32:85-94.

28 Lewis A, Cave P, Stern M, et al. Singing for lung Health-a systematic review of the literature and consensus statement. NPJ Prim Care Respir Med 2016;26:16080.

29 Gick ML, Nicol JJ. Singing for respiratory health: theory, evidence and challenges. Health Promot Int 2016;31:725-34.

30 McNamara RJ, Epsley C, Coren E, et al. Singing for adults with chronic obstructive pulmonary disease (COPD). Cochrane Database Syst Rev 2017;12:CD012296.

31 Durham University's Institute for Medical Humanities (IMH). Singing for breathing. Available: https://lifeofbreath.org/2016/03/singing-forbreat

32 Lewis A, Cave P, Hopkinson NS. Singing for lung health: a qualitative assessment of a British lung Foundation programme for group leaders. BMJ Open Respir Res 2017;4:e000216.
33 Lewis A, Cave P, Hopkinson NS. Singing for lung health: evaluation of the British lung Foundation programme, 2018.

34 Lewis A, Thomas J. Copd and singing for lung health: a patient and clinician perspective. Pulm Ther 2018;4:121-4.

35 TV2 Nord. KOL-patienter tog affære - nu er populært lunge-kor tilbage, 2018. Available: https://www.tv2nord.dk/jammerbugt/kolpatienter-tog-affaere-nu-er-populaert-lunge-kor-tilbage

36 SN (SjællandskeNyheder). Korsang hjælper KOL-patienter I Greve, 2016. Available: https://sn.dk/Greve/Korsang-hjaelper-KOLpatienter-i-Greve/artikel/546402

37 Danmarks Radio. Astmaramte Janne: Jeg ER blevet gladere AF at synge I lungekor, 2017. Available: https://www.dr.dk/nyheder/ regionale/trekanten/astmaramte-janne-jeg-er-blevet-gladere-afsynge-i-lungekor

38 Familiejournalen:. Rosa har KOL: Jeg bli'r så glad i låget, når jeg synger, 2018. Available: https://www.familiejournal.dk/livshistorier/ mennesker-imellem/rosa-har-kol-jeg-blir-saa-glad-i-laaget-naar-jegsynger

39 TV MidtVest. KOL-kor i Struer: - Vi kan synge, selvom vi snart ikke har luft, 2018. Available: https://www.tvmidtvest.dk/struer/kol-kor-istruer-vi-kan-synge-selvom-vi-snart-ikke-har-luft

40 The Danish Lung Foundation. Collaborations and projects, 2020. Available: https://www.lunge.dk/om-os/viden-samarbejder-ogprojekter

41 SurveyXact. SurveyXact by Rambøll management consulting, Aarhus, Denmark. Available: www.surveyxact.com

42 Bennett C, Khangura S, Brehaut JC, et al. Reporting guidelines for survey research: an analysis of published guidance and reporting practices. PLoS Med 2010;8:e1001069.

43 Kelley K, Clark B, Brown V, et al. Good practice in the conduct and reporting of survey research. Int J Qual Health Care 2003;15:261-6.

44 Graneheim UH, Lundman B. Qualitative content analysis in nursing research: concepts, procedures and measures to achieve trustworthiness. Nurse Educ Today 2004;24:105-12.

45 Jensen A. The benefits and challenges of interdisciplinary collaborations in arts and health practice. University of Nottingham, 2017.

46 Stenberg $\mathrm{H}$. How is the artist role affected when artists are participating in projects in work life? Int J Qual Stud Health Wellbeing 2016;11:30549.

47 Simonÿ C, Andersen IC, Bodtger U, et al. Accommodating to a troubled life - chronic obstructive pulmonary disease patients' experiences and perceptions of self-image during the course of rehabilitation. Disabil Rehabil 2020;42:2510-8.

48 Danish Board of Health. Early Rehabilitation of Patients with COPD after exacerbation [Danish, 2014.

49 McNaughton A, Weatherall M, Williams M, et al. Sing your lungs Out-a community singing group for chronic obstructive pulmonary disease: a 1-year pilot study. BMJ Open 2017;7:e014151. 